\title{
Simulating more accurate snow maps for Norway with MCMC parameter estimation method
}

\section{T. M. Saloranta}

Section for glaciers, snow and ice, Hydrology department, Norwegian water resources and energy directorate (NVE), Postboks 5091 Majorstua, 0301 Oslo, Norway

Received: 11 February 2014 - Accepted: 7 April 2014 - Published: 23 April 2014

Correspondence to: T. M. Saloranta (tus@ nve.no)

Published by Copernicus Publications on behalf of the European Geosciences Union.
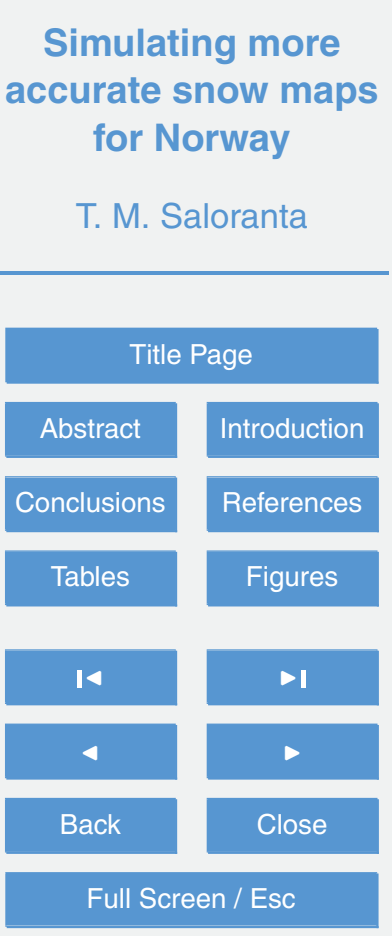

Printer-friendly Version

Interactive Discussion 


\section{Abstract}

The seNorge snow model produces daily updated maps $(1 \mathrm{~km} \times 1 \mathrm{~km}$ resolution $)$ of snow conditions for Norway which are used by the national flood, avalanche and landslide forecasting services, among others. The snow model uses gridded observations 5 of daily temperature and precipitation as its input forcing. In this paper the revisions made to the new seNorge snow model code (v.1.1.1) are described, and a systematic model analysis is performed by first revealing the most influential key parameters by the Extended FAST sensitivity analysis and then estimating their probability distributions by the MCMC simulation method, using 565 observations of snow water equivalent (SWE) and snow density $(\rho)$. The MCMC simulation resulted in rather narrow posterior distributions for the four estimated model parameters, and enhanced the model performance and snow map quality significantly, mainly by removing the known significant overestimation biases in SWE and $\rho$. In the new model version (v.1.1.1) the Nash-Sutcliffe (NS) model performance values are now well positive (NS $=0.61$ for SWE and NS $=0.30$ for $\rho$ ), in contrast to the much lower negative NS-values of the previous model (v.1.1). Moreover, the model evaluation against approximately 400000 point measurements of snow depth shows improvement in the simulated percentage of "good match"-stations (76-84\% before April, and still $65 \%$ at the end of April). Future research efforts should focus on decreasing the variability in the model fit with observations (i.e. model precision) by further improvements in the seNorge snow model and its important fundament, the gridded meteorological input data set used as its forcing.

\section{Introduction}

A significant fraction of the annual precipitation in Norway (approximately $30 \%$ ) falls as snow, and thus snow conditions play an important role in, among others, hydropower production planning, and in forecasting the risk of potentially disastrous floods, slush flows and avalanches. Snow is a prerequisite for many winter sport activities, and
Simulating more accurate snow maps for Norway

T. M. Saloranta

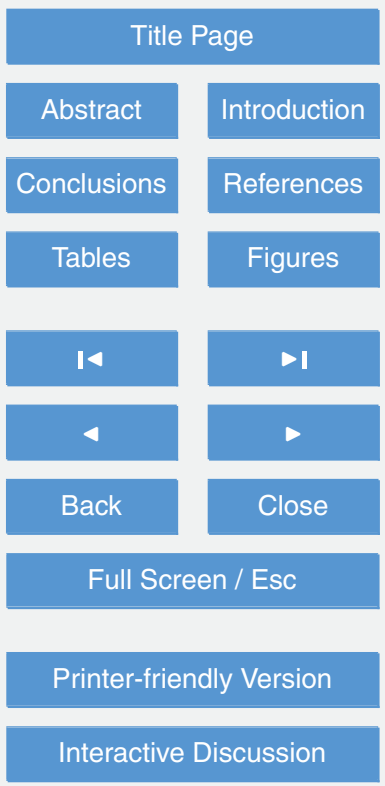


a challenge for construction safety and for traffic flow at airports and on roads and railways. Snow cover is also a key factor in the weather and climate system, both regionally and globally.

To be able to better meet demands on providing updated detailed information on 5 regional snow conditions in Norway, national snow maps (Fig. 1) have been produced at the Norwegian Water Resources and Energy Directorate (NVE) with the seNorge snow model since 2004 (Tveito et al., 2002; Engeset et al., 2004a, b; Saloranta, 2012), in co-operation with the Norwegian Meteorological Institute (MET). Since snow conditions vary strongly with the date of the snow season, region, elevation, and the type 10 of winter (e.g. cold and dry vs. wet and warm winters, depending on the type of the large scale atmospheric circulation patterns), models at small enough spatiotemporal resolution are indeed needed to resolve the rather high variability in snow conditions in the mountainous Norway.

The seNorge snow model simulates different snow-related variables, such as snow water equivalent (SWE), snow depth (SD), bulk snow density $(\rho=\mathrm{SWE} / \mathrm{SD})$, and the amount of liquid water in the snowpack $\left(W_{\mathrm{L}}\right)$. In the operational production of the snow maps, gridded values of daily mean temperature and daily sum of precipitation are used as the model forcing data. This input data is produced by MET and is based on spatial interpolation of available temperature and precipitation observations to a grid with $1 \mathrm{~km} \times 1 \mathrm{~km}$ resolution (Tveito et al., 2005; Mohr, 2008, 2009). Consequently, a snow map for Norway consists of simulated snow conditions in approximately 324000 $1 \mathrm{~km} \times 1 \mathrm{~km}$ grid cells covering Norway. These maps are published at www.seNorge.no (Fig. 1), and the time series of daily snow maps go back to 1957. The simulation results are freely available, and the maps are used, for example, in composing weekly reports on snow conditions, hydropower production and power system planning, as well as in forecasting of runoff, floods and the risk of avalanches. They can also help the public for checking e.g. skiing conditions, and be applied in scientific studies.

The seNorge snow model evaluation studies (Engeset et al., 2004b; Stranden, 2010; Dyrrdal, 2010; Saloranta, 2012) have pointed out some significant systematic biases

Simulating more accurate snow maps for Norway

T. M. Saloranta

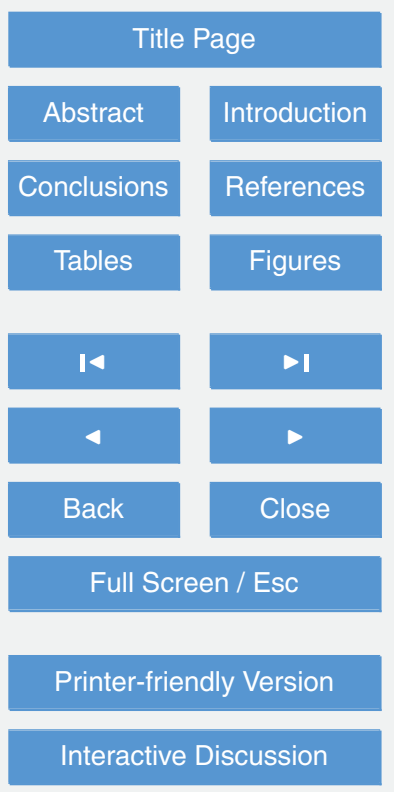


in the simulated snow conditions. A recent statistical evaluation study by Saloranta (2012) compared the seNorge model simulations against two large datasets from the hydropower companies and MET and confirmed the previous evaluation results on that the seNorge model generally overestimates SWE and $\rho$. Moreover, the distribution 5 of model fit for SWE showed a clear dependency on elevation throughout the snow season. E.g., around the end of March, the model overestimated SWE on average by $+34 \%$ in the $400-600$ ma.s.l. elevation interval, while by as much as $+100 \%$ in the higher 1000-1200 ma.s.l. elevation interval. The seNorge model was found to overestimate also $\rho$ by $0.1 \mathrm{~kg} \mathrm{~L}^{-1}$ on average, but there was less variation in the model fit 10 along the snow season and elevation for $\rho$. The $R^{2}$-values in Saloranta (2012), however, indicated that the model performs rather well in simulating the observed variability in SWE and $\rho$, despite of the overestimation of absolute values. Due to the known systematic biases, one has usually been bound to use relative snow conditions (e.g. comparisons of current SWE to a 30 year median SWE) instead of absolute values 15 in practical applications. The lack of accurate absolute values of snow conditions has been a considerable limitation for many existing and potential new applications of the snow maps.

The main aim of this study is to increase the quality of the seNorge model results and the snow maps for Norway by revising the model code (especially the density and snow melt algorithms), as suggested in Saloranta (2012), and to estimate the parameters (i.e. "calibrate") of the new model version 1.1 .1 by using the Markov chain Monte Carlo (MCMC) simulation method, in combination with model sensitivity analysis. The MCMC simulation method is based on Bayesian inference, and is able to reveal all plausible parameter combinations that give a proper model fit with observations, taking also into account uncertainty in the model, input data and observations. In addition, previous knowledge on the distribution of parameter values can be utilized in MCMC simulation in form of prior distributions and contribute to the parameter estimation. Before the MCMC-simulation, a sensitivity analysis is performed in order to point out the most influential parameters for the different model output variables at different climate

Simulating more accurate snow maps for Norway

T. M. Saloranta

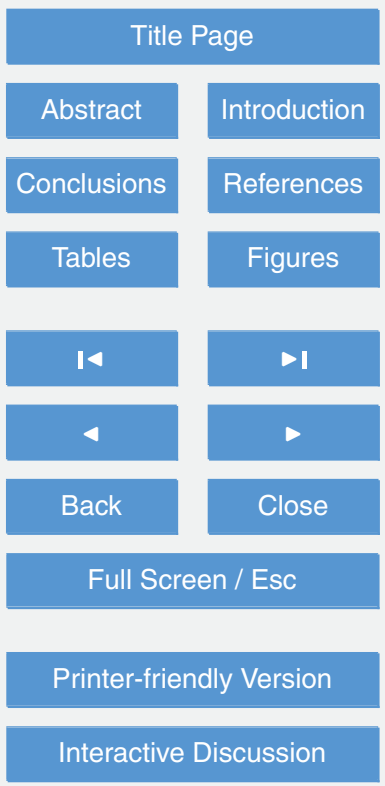


types and dates of the snow season. These key parameters revealed in the sensitivity analysis are then "tuned" in the MCMC-simulation to optimize the model fit against observations of SWE and $\rho$. The "R" statistical software (www.r-project.org) is applied for all model analysis.

\section{Model code (v.1.1.1) description and sensitivity analysis}

The seNorge snow model requires the daily mean air temperature $T\left[{ }^{\circ} \mathrm{C}\right.$ ] and the daily sum of precipitation $P$ [mm] as input forcing, and the model consists of two main modules, namely (1) the SWE model for snow pack water balance and (2) the snow compaction and density module for converting SWE to SD. Note that the SWE submodel is independent of the snowpack compaction and density submodel, implying that SWE is not affected by snow density in the model. The equations of the previous seNorge snow model version (v. 1.1) have been presented in details in Saloranta (2012). The changes made into the revised code (v. 1.1.1) are described in the following sections, and their purpose is to correct the detected weaknesses in the code and to increase the model performance. The 13 main model parameters of the revised code and their default or optimized values are summarized in Table 1.

\subsection{Modifications made to the new model code (v. 1.1.1)}

\subsubsection{SWE model for snowpack water balance}

The snow melt simulation in the previous model code (v.1.1) was based on a degreeday approach, where the potential daily melting $M^{*}$ (actual melting $M$ is limited by the availability of ice) is

$M^{*}=C_{\mathrm{M}}\left(T-T_{\mathrm{M}}\right)$

8, 1973-2003, 2014

Simulating more accurate snow maps for Norway

T. M. Saloranta

Title Page

Abstract Introduction

Conclusions References

Tables Figures

14 DI

4

\section{Full Screen / Esc}

Printer-friendly Version

Interactive Discussion 
when the daily mean air temperature $T$ is above the melting threshold temperature parameter $T_{\mathrm{M}}$, and where the degree-day factor $C_{\mathrm{M}}\left[\mathrm{mmd}^{-1}{ }^{\circ} \mathrm{C}^{-1}\right]$ varies with the time of the year as a sinus-wave within a predefined range.

In the revised model code (v. 1.1.1), $M^{*}$ is formulated as

${ }_{5} \quad M^{*}=b_{0} T+c_{0} S^{*}$, if $T>0^{\circ} \mathrm{C}$

where $b_{0}$ and $c_{0}$ are empirical parameters and $S^{*}$ the daily solar irradiance $\left[\mathrm{MJ} \mathrm{d}^{-1}\right.$ ] on a horizontal plane (not taking into account attenuation in the atmosphere, and for simplicity normalized with irradiance at $60^{\circ} \mathrm{N}$ at summer solstice), which is a function of latitude and time of the year (see e.g. Walter et al., 2005). This code modification, as well as the estimation of the parameters $b_{0}$ and $c_{0}$, are based on results from a statistical analysis of 3356 daily snow melt rates from Norwegian snow pillow data (Saloranta, 2014). The new snowmelt formulation introduces thus an additional term to the degree-day algorithm, which is not dependent on the temperature, but is related to the seasonal and zonal variation in incoming short-wave radiation. The melting threshold temperature parameter $T_{\mathrm{M}}$ is fixed to $0^{\circ} \mathrm{C}$, and thus omitted from Eq. (1b).

The performance of the snow melt model in simulating the observed melt rates was in Saloranta (2014) tested in terms of the Nash-Sutcliffe value (NS; see Eq. 7). For the previous model code (v.1.1; Eq. 1a) the NS value was 0.31 and 0.03 for the forested and treeless grid cells, respectively. This model also underestimated the sum of all observed melt values by 7 and $13 \%$ for the forested and treeless grid cells, respectively. The revised snow melt model (v.1.1.1; Eq. 1b) showed better performance, as the NS values increased to 0.35 and 0.20 for the forested and treeless grid cells, respectively, and the melt sums were now exactly estimated (Saloranta, 2014). Moreover, the averof snow-covered area in the model grid cells (see Sect. 2.1.3). 


\subsubsection{Snowpack compaction and density model}

While the diurnal snow accumulation and melting processes have no particular order in the snowpack water balance submodel, the order of changes in SD in the compaction and density submodel matters, due to differences in the density of the old and new snow layers. The changes in SD were in the previous model code (v.1.1) calculated in the following order: (1) melting of old snowpack, (2) new snowfall, (3) melting of new snowfall, (4) instant compaction of the old snowpack due to weight of the new snowfall, (5) gradual viscous compaction of the snowpack. Note that Steps 1-3 can occur at the same time step if $T$ is in the range $0-0.5^{\circ} \mathrm{C}$ with current default parameter values. Otherwise, either Step 1 or 2 may occur, but Step 3 does not.

In the revised model code (v. 1.1.1) the Step 1 is formulated more precisely, Step 4 is omitted as unnecessary, and the formulation in Step 5 is revised, as described below.

The SD change in Step 1 due to melting of old snowpack is now formulated as

$\Delta \mathrm{SD}_{1}=-\frac{M}{W_{1}^{t-1}} \cdot \mathrm{SD}^{t-1}$, if $M>0$

where $W_{1}$ is the ice content in snow (expressed in water equivalents [mm]), and $(t-1)$ denotes values from the previous time step. As refreezing $(M<0)$ is not affecting SD, $M$ is restricted to positive values in Eq. (2).

The snow depth $\mathrm{SD}_{1}$ after the melting and/or new snow fall (Steps 1-3) becomes

20

$\mathrm{SD}_{1}=\mathrm{SD}^{t-1}+\Delta \mathrm{SD}_{1}+\frac{\min \left(W_{1}^{t}, P_{\mathrm{S}}\right)}{\rho_{\mathrm{ns}}}$

where $\rho_{\mathrm{ns}}$ is the density of new snow and $P_{\mathrm{S}}$ is new snow fall in water equivalents [mm], restricted to the current $W_{1}^{t}$, in case the whole old snowpack and part of the new snow was melted and the remaining new snow is the only snow left. The $\rho_{\mathrm{ns}}$ is as formulated in Saloranta (2012), but a minimum allowed value of $\rho_{\mathrm{ns}}=0.050 \mathrm{~kg} \mathrm{~L}^{-1}$ is now applied.

Simulating more accurate snow maps for Norway

T. M. Saloranta

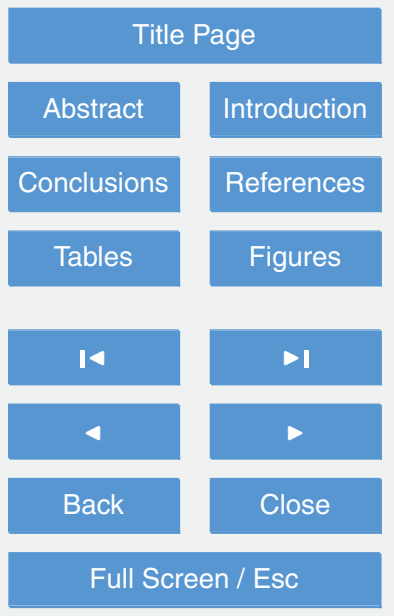

Printer-friendly Version

Interactive Discussion 
The instant compaction of the old snowpack due to weight of the new snowfall in Step 4 (Eq. 14a in Saloranta, 2012) is completely removed from the revised model code (v.1.1.1). This part of the compaction algorithm seems to be superfluous, and is actually not combined with the viscous compaction process (Step 5) in either the VIC 5 (Cherkauer and Lettenmaier, 1999) or SNTHERM (Jordan, 1991) models, which the v.1.1 compaction algorithm was based on.

The snow depth change due to gradual, viscous compaction of snow involves equation for the viscosity of snow $\eta\left[\mathrm{Nsm}^{-2}\right]$ (Step 5; Eq. 15a in Saloranta, 2012). In the revised model (v.1.1.1) the equation for $\eta$ follows the formulation in the Crocus snow 10 model (Vionnet et al., 2012) taking into account the decrease in $\eta$ when liquid water is present in the snow pack:

$\eta=\frac{1}{1+60 \frac{W_{\mathrm{L}}}{\mathrm{SD}_{1}}} \cdot \frac{\rho}{0.250} \cdot \eta_{0} \cdot \exp \left(-C_{5} T+C_{6} \rho\right)$

where $W_{L}$ is the liquid water content in the snowpack [mm], $\mathrm{SD}_{1}$ is snow depth [mm] from Eq. (3), and the constants 60 and $0.250 \mathrm{~kg} \mathrm{~L}^{-1}$ are fixed empirical parameters.

The final snow depth for the present time step $S^{t}$ is calculated as in Saloranta (2012)

$\mathrm{SD}^{t}=\mathrm{SD}_{1}+\Delta \mathrm{SD}_{2}$

20 Furthermore, the daily density increase cannot exceed a doubling, and the density values are restricted below the maximum allowed value of $0.550 \mathrm{~kg} \mathrm{~L}^{-1}$.

\subsubsection{Model for simulating the snow distribution and fraction of snow-covered area in the model grid cells}

Snow depth, and consequently SWE, show a strong spatial variability (see e.g. Clark et al., 2011). For example, in mountainous areas the interplay of topography and wind redistribution of snow can cause snow depths to vary from zero (bare ground) to a few
8, 1973-2003, 2014

Simulating more

accurate snow maps

for Norway

T. M. Saloranta

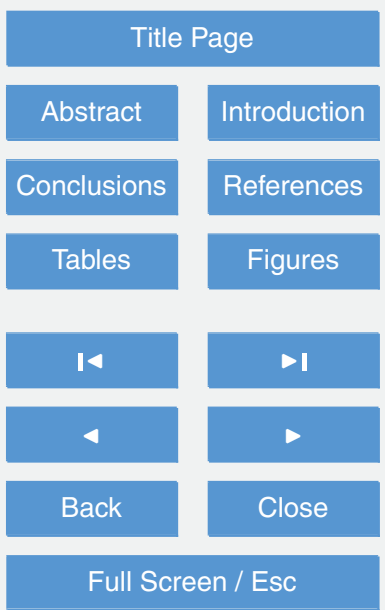

Printer-friendly Version

Interactive Discussion 
meters on a short distance of a few tens of meters. In the previous seNorge snow model code (v.1.1), no spatial variability of SD or SWE was simulated within the model $1 \mathrm{~km} \times 1 \mathrm{~km}$ grid cells. In order to simulate (1) the subgrid spatial variability of SWE and (2) the fraction of snow-covered area (SCA) within the model grid cells, a new submodel 5 is implemented in the revised model code (v.1.1.1). This new submodel is inspired by the snow distribution algorithm in the VIC model (Cherkauer et al., 2003), and it assumes that snow is distributed as the uniform distribution $U$ ( $\min$, max) within the grid cells, i.e. that all SWE values between a defined minimum and maximum value are equally likely within the snow-covered part of the grid cell. The "box-shaped" uniform 10 distribution is one of the simplest probability distributions, but has several advantages in the snow distribution algorithm, as it is simple to integrate, preserves its "form" even when truncated, and is symmetric around the mean value. The min-max variability range of SWE is assumed to be proportional (by a factor $f_{\mathrm{var}}$ ) to the highest SWE reached so far in the snow season.

Moreover, if $\mathrm{SCA}<1$, an even layer of new snow can form on top of the uniformly distributed "old" snow pack (SCA is then set to 1). If this new snow layer is completely melted again, the SCA value of the "old" snow pack $(\mathrm{SCA}<1)$ beneath the new snow layer is applied again. When the thickness of the new snow layer reaches an upper limit, which is dependent on the variability parameter $f_{\text {var }}$, then the new snow layer is merged into the uniformly distributed snow pack.

Figure 2 illustrates the main concept of the subgrid snow distribution model. The main consequence of implementing this model is the reduction of the mean snow melting (or refreezing) rate for the partly bare grid cells, i.e. when SCA $<1$. This effect is often especially pronounced in the late melting season.

The snow distribution and SCA model are described in more details in Saloranta (2014).

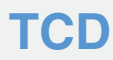

8, 1973-2003, 2014

Simulating more

accurate snow maps for Norway

T. M. Saloranta

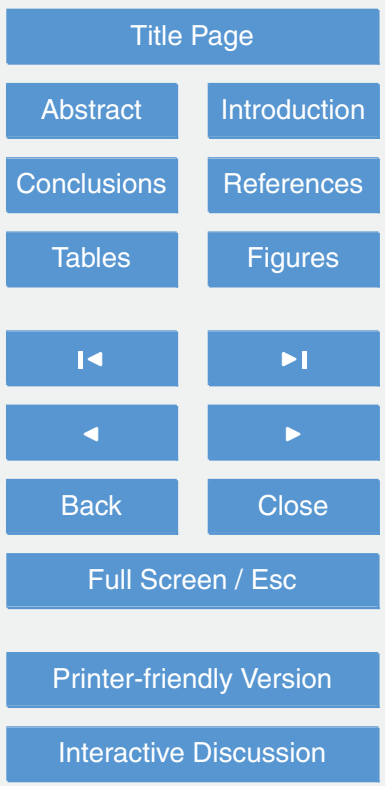




\subsection{Model sensitivity analysis}

The sensitivity of the different seNorge model output variables to the 13 main model parameters (Table 1) were analysed by the Extended Fourier Amplitude Sensitivity Test (Extended FAST; Saltelli et al., 1999, 2000), using the package "sensitivity" available

5 for the "R" statistical software. In the sensitivity analysis the model is run 65000 times for each test site (see below) and sensitivity indices are calculated for each analyzed parameter. The indices reflect both the parameters' role in the model code and their plausible value ranges. The definition of these ranges (Table 1) was based on the author's expert judgement as well as literature.

10 Sensitivity analysis results were produced for four different 10 day time windows around the beginning of January, March, April, and May, as well as for three climatically different test sites, for the 5-year period from 1 September 2004 to 31 August 2009. The three test sites were (1) a relatively warm and wet "maritime" site (winter (DJFM) mean $T=3.6^{\circ} \mathrm{C}$ and sum $P=1300 \mathrm{~mm}$ ), (2) an "intermediate" site (winter (DJFM) mean $T=-1.2^{\circ} \mathrm{C}$ and sum $P=920 \mathrm{~mm}$ ), and (3) a relatively cold and dry "continental" site (winter (DJFM) mean $T=-6.0^{\circ} \mathrm{C}$ and sum $P=430 \mathrm{~mm}$ ). Since SWE and $\rho$ are the most relevant output variables for the current model parameter estimation task (see Sect. 3.2), the sensitivity analysis results of these variables are of special interest. Mean values of $\rho$ and log-transformed SWE over the 10 day time windows and over the five simulated snow seasons in 2004-2009 were used in calculation of the sensitivity indices.

The results from the sensitivity analysis indicate that SWE is always most sensitive to the input precipitation bias correction parameter $f_{\mathrm{s}}$, and density $\rho$ is always most sensitive to density-viscosity relation parameter $C_{6}$, except for the "maritime" test station, where the input temperature bias correction parameter $T_{\text {cor }}$ is approximately as influential as $f_{\mathrm{s}}$. These results are much as expected, taking into account that these parameters clearly play an important role in the model code for SWE and $\rho$, and have

Simulating more accurate snow maps for Norway

T. M. Saloranta

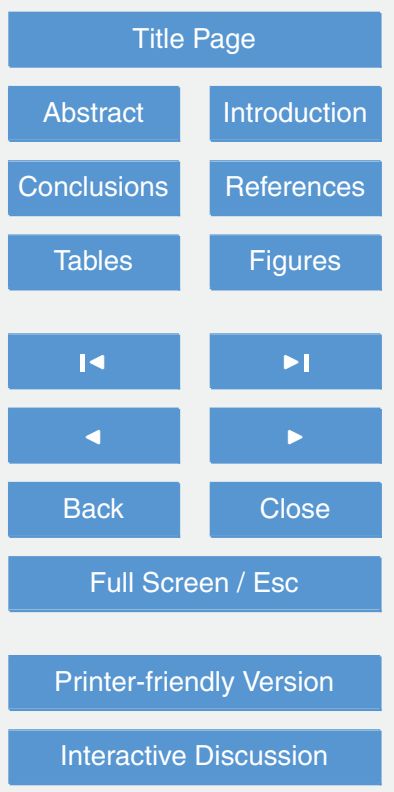


in addition rather wide ranges of plausible values (Table 1). Figure 3 illustrates the sensitivity indices for the "intermediate" test site around the beginning of April.

In some cases, especially on the "maritime" test station, SWE and $\rho$ are also somewhat sensitive to the snow melt parameter $b_{0}$, threshold temperature for precipitation 5 as snow $T_{S}$, and to the coefficient related to viscosity of snow $\eta_{0}$.

\section{Model parameter estimation (MCMC simulation)}

\subsection{The MCMC simulation method}

The MCMC simulation method (see e.g. Gamerman, 1999; Saloranta et al., 2009) was applied to estimate parameter values in the seNorge snow model. This method is based on Bayesian inference and is suitable for automatic model calibration and uncertainty analysis. The MCMC simulation techniques have previously been used in connection with snow modelling by e.g. Kolberg and Gottschalk (2006) and He et al. (2011). The general idea of MCMC simulation is based on a "guided" random walk in the parameter space, where the posterior distributions of the model parameters are estimated on the basis of the parameters' prior distributions and the likelihood of the model simulations. Namely, according to the Bayes' rule, posterior probability is proportional to prior probability times the likelihood, i.e. $\operatorname{Pr}(p \mid y) \propto \operatorname{Pr}(p) \cdot \operatorname{Pr}(y \mid p)$, where $p$ denotes parameters and $y$ observations. A large number of iterations (i.e. model runs) are executed and after the chain of the random "steps" in the parameter space has properly converged to a distribution, it represents samples of parameter sets which optimally, in a probabilistic sense, fits the corresponding model results to the corresponding observations used in the MCMC simulation. In other words, the chain represents samples from the posterior joint probability distribution of all the estimated parameters. Thus, the parameter unidentifiability (or equifinality) problem (Beven, 2006), i.e. that several different parameter value combinations can produce similar simulation results, can be resolved and represented in the MCMC simulation. 
Before the actual MCMC simulation is started, the so-called prior distributions are defined, reflecting our previous knowledge (or lack of that) on the probability of different parameter values. On each iteration round in the MCMC simulation, a likelihood measure $L$ is calculated for the $M$ observations $H^{\text {obs }}$, given the corresponding $M$ model 5 results $H^{\text {mod }}$ simulated with the currently proposed parameter values:

$L \propto \frac{1}{\prod_{i=1}^{M} \sigma_{i}} \exp \left(-\sum_{i=1}^{M} \frac{1}{2 \sigma_{i}^{2}}\left(H_{i}^{\mathrm{obs}}-H_{i}^{\mathrm{mod}}\right)^{2}\right)$

where $L$ is here based on normal distributed deviations between the model and observations, and where $\sigma^{2}$ is the error variance, representing errors in input data, observations and in model simulations. The observation error in our case includes both measurement error and uncertainty of the spatially limited observations in capturing the mean SWE and $\rho$ in the $1 \mathrm{~km} \times 1 \mathrm{~km}$ grid cell area, which the model results are assumed to represent. Figure 4 shows a graphical illustration of the Bayesian model assumed in our MCMC simulations.

\subsection{The MCMC simulation setup for the seNorge snow model}

On the basis of the overall results from the sensitivity analysis (Sect. 2.2) the two generally most influential parameters, $f_{\mathrm{s}}$ and $C_{6}$, were selected to be estimated in the MCMC simulation. Although $T_{\text {cor }}$ was found to be influential especially on the warm and wet test station, it was not included in the current MCMC simulation due to lack of information and evidence on the possible sign and magnitude of any large-scale systematic bias in the gridded temperature input data. In addition, the interpolation error in temperature (if any) would be expected to be largest at the higher elevation levels where the MET-station density is low, and where the model is likely to be less sensitive to $T_{\text {cor }}$ due to colder temperatures. On the contrary, the generally more unknown vertical

precipitation gradients and catch correction factors, as well as the steadily increasing 
bias in SWE with elevation, detected in Saloranta (2012), suggests that $f_{\mathrm{s}}$ could be significantly different from one and vary with elevation. Consequently, this input correction parameter was included in the current MCMC simulation, and was further defined as a function of elevation, using a piecewise linear relation involving three parameters 5 (see Saloranta (2014) for details). Two $\left(f_{\mathrm{s}_{-} 0}, f_{\mathrm{s}_{-} 1}\right)$ of these three parameters describe the linear model, and the third parameter $\left(z_{\max }\right)$ the elevation level above which $f_{\mathrm{s}}$ stays constant at the value at $z_{\max }$. In addition, $f_{\mathrm{s}}$ is restricted to values between 0 and 1 . The rest of the parameters, that were not estimated in the MCMC simulation, were fixed to their default values (Table 1).

10 The snow observations of SWE and $\rho$ used in the optimization of the values of $f_{\mathrm{S}_{0} 0}$, $f_{\mathrm{s}_{-} 1}, Z_{\max }$ and $C_{6}$ come from 194 stations of the various hydropower companies (HPCdata; Fig. 5). These stations are a subsample of the entire dataset used in the previous seNorge model evaluation (Saloranta, 2012), and the station sampling in this subset is designed so that the different regions and elevations are represented in a more bal15 anced way than in the complete dataset, where a majority of the stations is located on a central mountain area in southern Norway. From each station four (or less if not available) random years are extracted from the time series, and data from three different time windows around the beginning of January, March and April are used (if available). The total number of observations used in the MCMC simulation is 565 for both SWE and $\rho$. Figure 5 summarizes the spatiotemporal and value distribution of these observations. The reported values of $\rho$ are normally based on one or more point observations, and those of SWE on an average of many spatially distributed snow depth soundings around the station or along a snow course.

Before the start of the MCMC simulation, rather wide uniform prior distributions are defined for the four key parameters, specifying the reasonable minimum and maximum allowed values for the parameters. Log-transformation of SWE in the MCMC simulation was tested, since the error variance for SWE may be somewhat heteroscedastic. However, in order to retain weight of the larger SWE values in the parameter optimization, the original untransformed data was used in the final MCMC simulation. The
Simulating more accurate snow maps for Norway

T. M. Saloranta

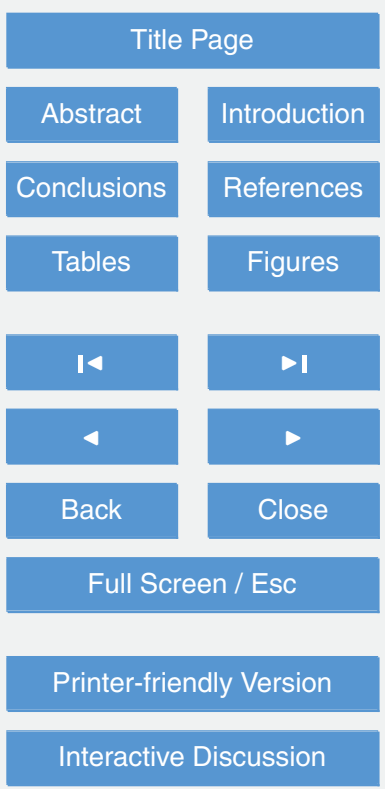


two overall error variances, one for SWE and one for $\rho\left(\sigma_{\text {SWE }}^{2}, \sigma_{\rho}^{2}\right)$, were estimated on each MCMC iteration round by Gibb's sampling (e.g., Gamerman, 1999; Larssen et al., 2006; non-informative priors assumed). The MCMC routine in the package "FME" for the "R" statistical software was used, featuring adaptive Metropolis-Hastings algorithm 5 with delayed rejection. The production of simulation results corresponding to the 565 snow observations (i.e. one iteration) took approximately $45 \mathrm{~s}$ on a PC with $2.8 \mathrm{GHz}$ clock speed, and a total number of 2000 iterations were run in the final MCMC simulation. The parameter proposal acceptance rate in the MCMC simulation was rather high $(30 \%)$. Figure 4 shows as an example the parameter chain as well as the prior and posterior distributions for $C_{6}$.

After the initial adaptation phase, the simulated parameter chains were visually investigated for convergence. The chain distributions indicated that the prior distributions were well updated to rather narrow posterior distributions (see Fig. 4 for example). However, the parameter uncertainty revealed by the MCMC simulation was at this stage not utilised further in the operational snow map application, but this task was left to a future snow map uncertainty analysis. Consequently, only the "best fit" values (i.e. those giving the maximum likelihood in MCMC simulation) for the parameters $f_{\mathrm{s}_{-} 0}, f_{\mathrm{s}_{-} 1}, z_{\max }$ and $C_{6}$ were used in the revised model. The improvement in model performance after the parameter estimation was evaluated by the Nash-Sutcliffe (NS) measure:

$20 \mathrm{NS}=1-\frac{\sum_{i=1}^{M}\left(H_{i}^{\mathrm{mod}}-H_{i}^{\mathrm{obs}}\right)^{2}}{\sum_{i=1}^{M}\left(H_{i}^{\mathrm{obs}}-\bar{H}^{\mathrm{obs}}\right)^{2}}$

A NS value of 1 indicates a perfect model fit, and negative values that the model performance is worse than simply using the observed mean as a naive model.
TCD

8, 1973-2003, 2014

Simulating more

accurate snow maps

for Norway

T. M. Saloranta

Title Page

Abstract

Introduction

Conclusions

References

Tables

Figures

14

$\Delta$

4

Back

Close

Full Screen / Esc

Printer-friendly Version

Interactive Discussion 


\section{Results}

The consequence of the distributions and optimized values for $f_{\mathrm{s}_{-} 0}, f_{\mathrm{s}_{-} 1}, z_{\max }$ from the MCMC simulation is that the input snow precipitation is significantly adjusted, depending on the model grid cell elevation. The posterior distribution of the slope parameter

$5 f_{\mathrm{s}_{-} 1}$ is significantly different from zero, and the resulting bias correction factor $f_{\mathrm{s}}$ of input precipitation (as snow) decreases gradually with elevation, the endpoints being so that below 200 ma.s.I. no correction is made $\left(f_{\mathrm{s}}=1.0\right)$, and above 700 ma.s.l. $38 \%$ of the input precipitation is removed $\left(f_{\mathrm{s}}=0.62\right)$. This kind of input correction is justified, since most of the MET-stations used in the gridding of the input data are located in lowland areas, and thus the interpolated values at higher elevations are associated with more uncertainty connected to the vertical precipitation gradients and precipitation catch correction factors applied in the gridding method (Mohr, 2008). The optimized value for the parameter $C_{6}$ is $24.3 \mathrm{~L} \mathrm{~kg}^{-1}$ and is thus somewhat higher than the default value of $21 \mathrm{~L} \mathrm{~kg}^{-1}$, meaning that the snow viscosity and its increase with density are generally 15 higher in the revised model. Furthermore, the posterior distribution of $C_{6}$ (Fig. 4) shows that the revised value is significantly different from the default value, but still far from the endpoints of the plausible prior range set roughly to $15-35 \mathrm{~L} \mathrm{~kg}^{-1}$ on the basis of the values for maritime/alpine snow in Sturm and Holmgren (1998).

The evaluation of the revised model, both visually (Fig. 6) and in terms of the model bias, the squared correlation coefficient $R^{2}$ and the NS performance indicators (Table 2), shows that especially the model accuracy got better (less bias), while the precision did not improve significantly (not less variability). As Fig. 6 shows, the significant biases for SWE and $\rho$ along elevation, simulated by the previous (v.1.1) snow model, have been mostly removed in the new revised version (v.1.1.1). This is clearly reflected $=0.30$ for $\rho$ ), in contrast to those of the previous model which were poor (negative values; NS $=-0.54$ for SWE and NS $=-1.70$ for $\rho$ ) due to the large systematic errors. The NS value for $\rho$ increases further to 0.37 when removing the lowest SWE fraction
Simulating more accurate snow maps for Norway

T. M. Saloranta

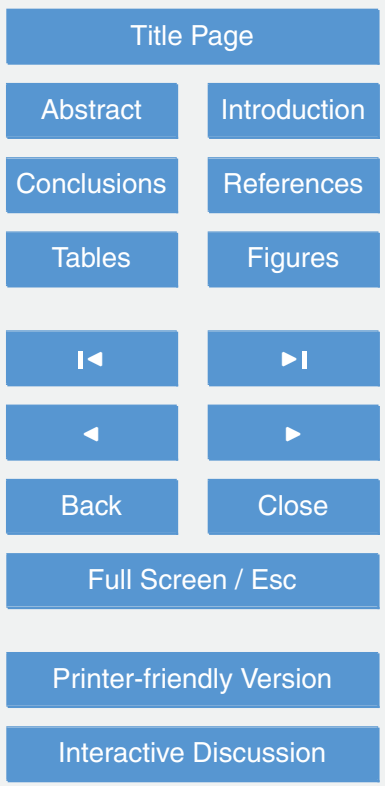


$(<100 \mathrm{~mm}$ ) of the data, which is often associated with snow from the very early or late part of the season with corresponding densities from the lower and higher ends of the density range.

In the same way as in the study of Saloranta (2012), a model evaluation was made 5 against an extensive set of snow depth (SD) measurements recorded at the METstations (nearly 400000 measurements). This data was not used to estimate parameters in the MCMC simulation and can thus be considered as "independent data". The evaluation against these SD observations shows that the new revised model version gave improved results compared to the previous (v.1.1) model. Especially the spring 10 overestimation in SD is corrected in the new version and the number of "good match"stations in the end of April is significantly increased. Namely:

- In evaluation of the previous version (v.1.1; Saloranta (2012)) the average stationwise median bias was within -14 to $+22 \%$ from January through March. At the end of April, however, the median bias was $+25 \%$ in the 0-200 ma.s.l. bin, and as much as $+108 \%$ in the $400-600$ ma.s.I. bin. The percentage of "good match"stations was $72-83 \%$ before April, but decreased to $42 \%$ at the end of April.

- The same evaluation made for the new version (v.1.1.1) shows that the average station-wise median bias is within -12 to $+17 \%$ all the way from January to the end of April. The percentage of "good match"-stations is $76-84 \%$ before April, and still $65 \%$ at the end of April.

It is worth bearing in mind, however, that the SD observations from the MET-stations are not perfectly well-suited for model evaluation and can give somewhat biased results. This is due to the fact that the bias in the gridded input data is likely less (but not zero) at the grid cells containing MET stations, than at most other model grid cells, where the interpolation error is larger. In addition, biased simulations of SWE and $\rho$ can potentially give a good match with SD for wrong reasons. In fact, this was the case in the previous version (v.1.1), where significant overestimation errors in both SWE and $\rho$ compensated each other, resulting in a more reasonable fit with SD (Saloranta,

Simulating more accurate snow maps for Norway

T. M. Saloranta

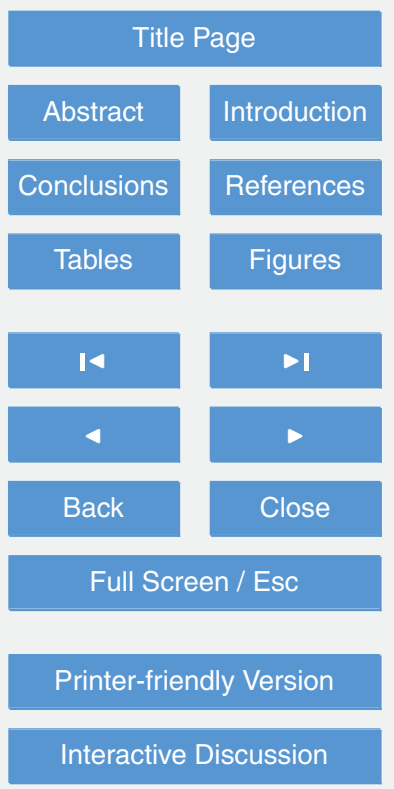


2012). Due to these two reasons, the MET-data was not used for parameter estimation in the MCMC simulation.

\section{Discussion}

The complete set of snow maps contains more than $6.7 \times 10^{9}$ seNorge model-simulated 5 values for each snow variable (SWE, SD, $\rho$, etc.). Compared to this huge amount of data, the number of the few hundreds of snow observations that could be applied in the parameter estimation is small. Consequently, a realistic aim for this study was to gain overall quality improvements on the snow maps by e.g. removing the detected systematic errors. In the task of "calibrating" the snow maps one has to operate in four - dimensions (latitude, longitude, elevation, time), and make many subjective choices underway on, e.g., how to choose a representative set of observations for the whole Norway, how to handle zero-values and whether to aim at minimizing the absolute or the relative difference between model and observations (absolute difference was selected in our case).

15 The combination of model sensitivity analysis and parameter estimation methods (Extended FAST and MCMC) performed well, where the former method revealed the set of key parameters which could be then estimated in the MCMC simulation simultaneously using observations of both SWE and $\rho$. Since these observations were obtained mostly during the main snow accumulation season (winter), snow melt related parameters of the revised snow melt algorithm and the new SCA submodel Saloranta (2014) could not be feasibly further refined in the MCMC simulation. The snow distribution parameter $f_{\text {var }}$ in the SCA submodel was roughly set on the basis of high-resolution snow depth data from $80 \mathrm{~km}$ transects measured by ground-penetrating radar (Ragulina et al., 2011), and expert judgment. The simulated SCA values are still to be evaluated against data from e.g. satellite images in future studies. However, even the roughly "tuned" SCA submodel brings more realism into the seNorge model by allowing spatial snow distribution and partly bare ground in the grid cells.
8, 1973-2003, 2014

Simulating more accurate snow maps for Norway

T. M. Saloranta

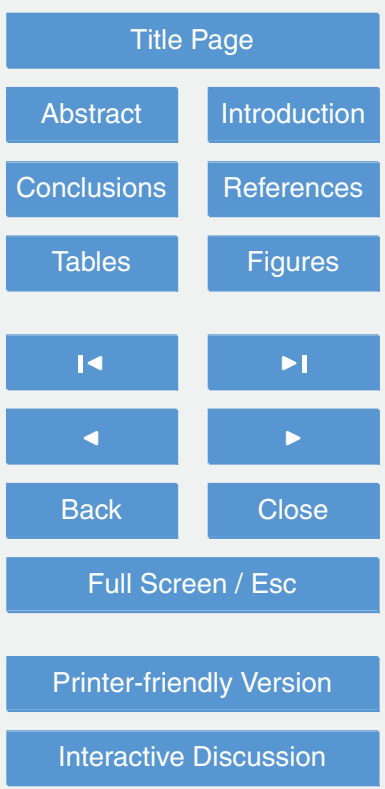


The posterior probability distributions of the model parameters, estimated in the MCMC simulation, allowed the examination of whether the optimized parameter values were significantly different from zero, or from previous default values. For example, if the bias correction parameters of $f_{\mathrm{s}_{0} 0}, f_{\mathrm{s}_{1} 1}$ and $T_{\text {cor }}$ would in a future MCMC simula5 tion, with an improved gridded input data set, turn out not to be significantly different from zero, that would be an indirect indication of a generally unbiased input data set. However, a rigorous separation of the input data and model errors can be methodologically challenging (Renard et al., 2010). The simulated parameter posterior distributions can also be used further in uncertainty analysis of the snow maps (see He et al., 2011).

The guiding principle in the model revision has been "right results for the right reasons". Thus, only those parameters that could be reasonably estimated on the basis of the SWE and $\rho$ observations were included in the MCMC simulation. The improvement in model performance for SWE was mainly connected to the adjustment of the input precipitation via the elevation-dependent parameter $f_{\mathrm{s}}$. The possible bias in the other model input variable, air temperature, was considered to be less significant than for the precipitation, as pointed out in Sect 3.2. The adjustment of the viscosity relation via parameter $C_{6}$ did remove the gross $0.1 \mathrm{kgL}^{-1}$ overestimation bias previously seen in $\rho$. However, the simulated density range seems to be still somewhat narrower than the observed density range (Fig. 6). Although inclusion of other parameters, such as the maximum water content in the snow pack or new snow density, could have led to even better model fit, these parameters seemingly cannot feasibly be estimated on the basis of the SWE and $\rho$ observations sampled only twice in the snow season.

The revisions made to the new snow maps seem to contribute to better overall snow map quality, as the large systematic biases have mostly been removed (better accuracy; compare model bias values in Table 2), and the physical process description of the model has improved. The new set of snow maps was operationally launched at the website www.senorge.no 1 September 2013. The quality of the snow maps will, however, still vary in both space and time, as in the previous version. Future research efforts should therefore focus on studying the sources of variability in the model fit
Simulating more accurate snow maps for Norway

T. M. Saloranta

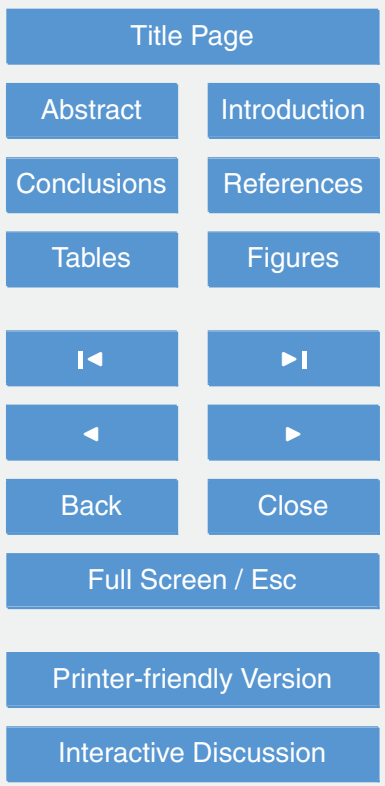


with observations (i.e. model precision). Namely, the adjustments made to the new snow model version have, somewhat disappointingly, not lead to significant reductions in this variability (compare $R^{2}$ values in Table 2), although the model accuracy was significantly increased. This variability between simulated and observed values can be

5 roughly divided to three main sources.

The first source of the variability is due to natural spatial variability and observation error, i.e. uncertainty in how well the observations can represent the mean conditions within the $1 \mathrm{~km} \times 1 \mathrm{~km}$ seNorge model grid cells. The second source of the variability is due to the errors in input forcing, i.e. how well the interpolated input forcing data repre10 sents weather conditions in a particular model grid cell. As pointed out above, this error probably generally increases along with the distance and elevation from nearest meteorological station used in the interpolation. Also measurement errors for precipitation (catch correction) contribute significantly here. The third source of the variability, between simulated and observed values, is due to the model parameter uncertainty (i.e. technical uncertainty) as well as due to the uncertainty in how well the seNorge model code, algorithms, and the applied daily time step represent the physics of the real snow accumulation, compaction and melting system (i.e. methodological uncertainty).

\section{Conclusions}

The snow maps for Norway are daily used in many applications, including the national avalanche, landslide and flood forecasting services, as well as hydropower production planning. Therefore, it is important to aim at best possible quality of these maps. The snow map evaluation study of Saloranta (2012) gave some recommendations which have been addressed in the current study, namely a revision of the density and snow melt algorithms and a new estimation of the corresponding model parameters, as well as a closer investigation of which elevation dependencies (or lack of them) in the model or forcing data could best explain and be used to remove the gross overestimation biases detected in SWE and $\rho$ in that study.

Simulating more accurate snow maps for Norway

T. M. Saloranta

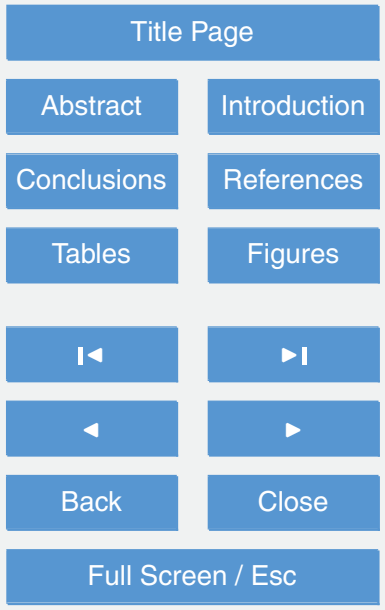

Printer-friendly Version

Interactive Discussion 
In order to perform a systematic and rigorous model analysis, and to minimize the number of optimized parameters, the most influential key parameters were first revealed by the Extended FAST sensitivity analysis and then estimated as probability distributions by the MCMC simulation method. The applied data set (565 observations 5 from 194 HPC-stations) is the most extensive used in seNorge model "calibration" so far, covering different parts of Norway and elevations from 125 to almost 1600 ma.s.l.

The MCMC simulation resulted in rather narrow posterior distributions for the four estimated parameters and enhanced the model performance and snow map quality significantly, mainly by removing the significant overestimation biases in SWE and $\rho$. 10 However, there is still potential and need for decreasing the variability in the model fit with observations (i.e. model precision). Future research efforts should therefore focus on bringing new data sources (e.g. satellite-based snow data) to the model analysis, and on developing and improving both the seNorge snow model and its important fundament, the gridded meteorological input data set used as its forcing.

15 Acknowledgements. Very special thanks to the various hydropower companies and to the Norwegian Meteorological Institute (MET) for provision of data, as well as to Jess Andersen for operational technical implementation of the seNorge model.

\section{References}

Beven, K.: A manifesto for the equifinality thesis, J. Hydrol., 320, 18-36, 2006.

Cherkauer, K. A. and Lettenmaier, D. P.: Hydrologic effects of frozen soils in the upper Mississippi River basin, J. Geophys. Res., 104, 19599-19610, 1999.

Cherkauer, K. A., Bowling, L. C., and Lettenmaier, D. P.: Variable infiltration capacity cold land process model updates, Global Planet. Change, 38, 151-159, 2003.

Clark, M. P., Hendrikx, J., Slater, A. G., Kavetski, D., Anderson, B., Cullen, N. J., Kerr, T., Hreinsson, E. Ö., and Woods, R. A.: Representing spatial variability of snow water equivalent in hydrologic and land-surface models: a review, Water Resour. Res., 47, W07539, doi:10.1029/2011WR010745, 2011.

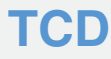

8, 1973-2003, 2014

Simulating more

accurate snow maps for Norway

T. M. Saloranta

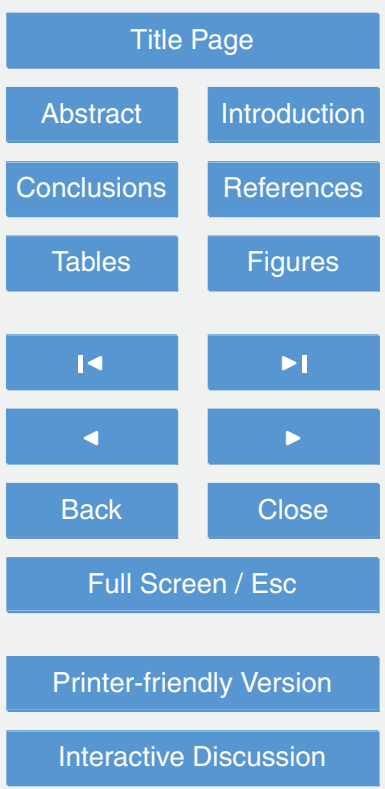


Dyrrdal, A. V.: An evaluation of Norwegian snow maps: simulation results vs. observations, Hydrol. Res., 41, 27-37, 2010.

Engeset, R., Tveito, O. E., Alfnes, E., Mengistu, Z., Udnæs, H.-C., Isaksen, K., and Førland, E. J.: Snow map system for Norway, in: NHP Report 48(1) from XXIII Nordic Hydro5 logical Conference, Tallinn, Estonia, 8-12 August 2004, 112-121, 2004a.

Engeset, R., Tveito, O. E., Udnæs, H.-C., Alfnes, E., Mengistu, Z., Isaksen, K., and Førland, E. J.: Snow map validation for Norway, in: NHP Report 48(1) from XXIII Nordic Hydrological Conference, Tallinn, Estonia, 8-12 August 2004, 122-131, 2004b.

Gamerman, D.: Markov Chain Monte Carlo: Stochastic Simulation for Bayesian Inference, Chapman \& Hall, London, UK, 1999.

He, M., Hogue, T. S., Franz, K. J., Margulis, S. A., and Vrugt, J. A.: Characterizing parameter sensitivity and uncertainty for a snow model across hydroclimatic regimes, Adv. Water Resour., 34, 114-127, 2011.

Jordan, R.: A One-Dimensional Temperature Model for a Snow Cover: Technical Documenta15 tion for SNTHERM.89, Special Report 91-16, US Army Cold Regions Research and Engineering Laboratory, Hanover, NH, USA, 49 pp., 1991.

Kolberg, S. A. and Gottschalk, L.: Updating of snow depletion curve with remote sensing data, Hydrol. Process., 20, 2363-2380, 2006.

Larssen, T., Huseby, R. B., Cosby, B. J., Høst, G., Høgåsen, T., and Aldrin, M.: Forecasting acid20 ification effects using a Bayesian calibration and uncertainty propagation approach, Environ. Sci. Technol., 40, 7841-7847, 2006.

Mohr, M.: New Routines for Gridding of Temperature and Precipitation Observations for "seNorge.no", met.no note 08/2008, The Norwegian Meterological Institute, Oslo, Norway, available at: http://met.no/Forskning/Publikasjoner/Publikasjoner_2008/filestore/ NewRoutinesforGriddingofTemperature.pdf (last access: 17 April 2014), 40 pp., 2008.

Mohr, M.: Comparison of Versions 1.1 and 1.0 of Gridded Temperature and Precipitation Data for Norway, met.no note 19/2009, The Norwegian Meterological Institute, Oslo, Norway, available at: http://met.no/Forskning/Publikasjoner/Publikasjoner_2009/filestore/note19-09. pdf (last access: 17 April 2014), 44 pp., 2009.

30 Ragulina, G., Melvold, K., and Saloranta, T.: GPR-Measurements of Snow Distribution on Hardangervidda Mountain Plateau in 2008-2011, NVE-report 8-2011, Norwegian Water Resources and Energy Directorate, Oslo, Norway, available at: http://webby.nve.no/ publikasjoner/report/2011/report2011_08.pdf (last access: 17 April 2014), 32 pp., 2011.

Simulating more

accurate snow maps for Norway

T. M. Saloranta

Title Page

Abstract Introduction

Conclusions References

Tables Figures

14

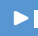

4

Back

Close

Full Screen / Esc

Printer-friendly Version

Interactive Discussion 
Renard, B., Kavetski, D., Kuczera, G., Thyer, M., and Franks, S. W.: Understanding predictive uncertainty in hydrologic modeling: The challenge of identifying input and structural errors, Water Resour. Res., 46, W05521, doi:10.1029/2009WR008328, 2010.

Saloranta, T. M.: Simulating snow maps for Norway: description and statistical evaluation of the seNorge snow model, The Cryosphere, 6, 1323-1337, doi:10.5194/tc-6-1323-2012, 2012.

Saloranta, T. M.: New Version (v.1.1.1) of the seNorge Snow Model and Snow Maps for Norway, Rapport 6-2014, Norwegian Water Resources and Energy Directorate, Oslo, Norway, available at: http://webby.nve.no/publikasjoner/rapport/2014/rapport2014_06.pdf (last access: 17 April 2014), 30 pp., 2014.

10 Saloranta, T. M., Forsius, M., Järvinen, M., and Arvola, L.: Impacts of projected climate change on the thermodynamics of a shallow and a deep lake in Finland: model simulations and Bayesian uncertainty analysis, Hydrol. Res., 40, 234-248, 2009.

Saltelli, A., Tarantola, S., and Chan, K.: A quantitative model-independent method for global sensitivity analysis of model output, Technometrics, 41, 39-56, 1999.

15 Saltelli, A., Chan, K., and Scott, E. M.: Sensitivity Analysis, Wiley, New York, USA, 2000.

Stranden, H. B.: Evaluering av seNorge: Data Versjon 1.1., Dokument 4/2010, Norges vassdrags- og energidirektorat (NVE) (in Norwegian), available at: http://webby.nve.no/ publikasjoner/dokument/2010/dokument2010_04.pdf (last access: 17 April 2014), 36 pp., 2010.

20 Sturm, M. and Holmgren, J.: Differences in compaction behavior of three climate classes of snow, Ann. Glaciol., 26, 125-130, 1998.

Sælthun, N. R.: The "Nordic" HBV Model, Publication nr. 7, The Norwegian Energy and Water Resources Administration (NVE), Oslo, Norway, available at: http://webby.nve.no/ publikasjoner/publication/1996/publication1996_07.pdf (last access: 17 April 2014), 26 pp., 1996.

Tveito, O. E., Udnæs, H.-C., Mengistu, Z., Engeset, R., and Førland, E. J.: New snow maps for Norway, in: NHP Report 47 from XXII Nordic Hydrological Conference, Røros, Norway, 4-7 August 2002, 527-532, 2002.

Tveito, O. E., Bjørdal, I., Skjelvåg, A. O., and Aune, B.: A GIS-based agro-ecological decision system based on gridded climatology, Meteorol. Appl., 12, 57-68, 2005.

Vionnet, V., Brun, E., Morin, S., Boone, A., Faroux, S., Le Moigne, P., Martin, E., and Willemet, J.-M.: The detailed snowpack scheme Crocus and its implementation in SURFEX v7.2, Geosci. Model Dev., 5, 773-791, doi:10.5194/gmd-5-773-2012, 2012.

Simulating more

accurate snow maps for Norway

T. M. Saloranta

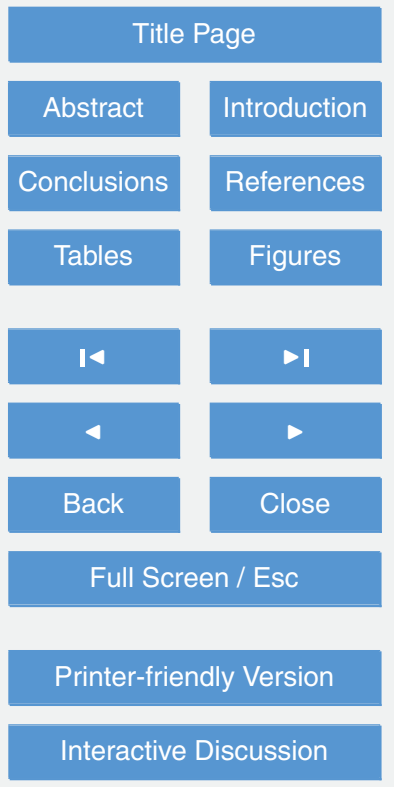


Walter, M. T., Brooks, E. S., McCool, D. K., King, L. G., Molnau, M., and Boll, J.: Process-based snowmelt modeling: does it require input data than temperature-index modeling?, J. Hydrol., 300, 65-75, 2005.

\section{TCD}

8, 1973-2003, 2014

\section{Simulating more} accurate snow maps for Norway

T. M. Saloranta

Title Page

\section{Full Screen / Esc}

Printer-friendly Version

Interactive Discussion 
Table 1. The 13 main seNorge snow model parameters with their default values, as well as the $\mathrm{min} / \mathrm{max}$ value ranges applied in the sensitivity analysis (see Sect. 2.2). Note that the default values of $f_{\mathrm{s}}$ and $C_{6}$ are replaced by the optimized values from MCMC simulation (Sect. 4).

\begin{tabular}{|c|c|c|c|c|c|}
\hline Parameters & Description & Default & Min & Max & Unit \\
\hline$f_{\mathrm{r}}$ & bias correction factor for input precipitation as rain & 1 & 0.5 & 1 & {$[-]$} \\
\hline$f_{\mathrm{s}}$ & bias correction factor for input precipitation as snow & 1 & 0.5 & 1 & {$[-]$} \\
\hline$T_{\text {cor }}$ & bias correction for input air temperature & 0 & -0.5 & 0.5 & {$\left[{ }^{\circ} \mathrm{C}\right]$} \\
\hline$r_{\max }$ & maximum allowed weight fraction $\left(W_{\mathrm{L}} / W_{1}\right)$ of liquid water in snowpack & 0.1 & 0.05 & 0.20 & {$[-]$} \\
\hline$T_{\mathrm{S}}$ & threshold air temperature for rain/snow & 0.5 & 0 & 0.5 & {$\left[{ }^{\circ} \mathrm{C}\right]$} \\
\hline$C_{\text {rf }}$ & degree-day refreezing factor & $0.16^{\mathrm{a}}$ & 0.08 & 0.40 & {$\left[\mathrm{mmd}^{-1}{ }^{\circ} \mathrm{C}^{-1}\right]$} \\
\hline$b_{0}$ & melt rate parameter (Eq. 1b) & $1.8-2.1^{b}$ & 1 & 3 & {$\left[\mathrm{mmd}^{-1}{ }^{\circ} \mathrm{C}^{-1}\right]$} \\
\hline$c_{0}$ & melt rate parameter (Eq. 1b) & $6-11^{b}$ & 5 & 10 & {$\left[\mathrm{mmd}^{-1}\right]$} \\
\hline$f_{\mathrm{var}}$ & spatial snow distribution parameter & $0.25-0.5^{\mathrm{b}}$ & 0.2 & 0.7 & {$[-]$} \\
\hline$\rho_{\mathrm{nsmin}}$ & minimum density of new snow & 0.050 & 0.050 & 0.150 & {$\left[\mathrm{kgL}^{-1}\right]$} \\
\hline$\eta_{0}$ & coefficient related to viscosity of snow (at zero temperature and density) & 7.6 & 1 & 10 & {$\left[\mathrm{MNsm}^{-2}\right]$} \\
\hline$C_{5}$ & coefficient for temperature effect on viscosity & 0.1 & 0.04 & 0.12 & {$\left[{ }^{\circ} \mathrm{C}^{-1}\right]$} \\
\hline$C_{6}$ & coefficient for density effect on viscosity & 21 & $15^{\mathrm{c}}$ & $35^{\mathrm{c}}$ & {$\left[\mathrm{Lkg}^{-1}\right]$} \\
\hline
\end{tabular}

\section{Simulating more}

accurate snow maps for Norway

T. M. Saloranta

\section{Title Page}

default value from the HBV model (Sælthun, 1996).

${ }^{\mathrm{b}}$ different values applied for forested and treeless grid cells (see Saloranta, 2014).

c value range based on Sturm and Holmgren (1998).

14

4

Back
$>1$

$>$

Close

Full Screen / Esc

Printer-friendly Version

Interactive Discussion 
Table 2. Comparison of model performance indicators for snow water equivalent (SWE) and bulk snow density $(\rho)$ between the previous (v.1.1) and the new revised versions (v.1.1.1) of the seNorge snow model. $R^{2}$ denotes the squared correlation coefficient, and NS the NashSutcliffe value (Eq. 7).

\begin{tabular}{lllllll}
\hline & \multicolumn{3}{c}{ SWE } & & \multicolumn{2}{c}{$\rho$} \\
& mean bias & $R^{2}$ & NS & mean bias & $R^{2}$ & NS \\
\hline seNorge v.1.1 & $+200 \mathrm{~mm}$ & 0.71 & -0.54 & $0.100 \mathrm{~kg} \mathrm{~L}^{-1}$ & 0.26 & -1.70 \\
new seNorge v.1.1.1 & $-5 \mathrm{~mm}$ & 0.68 & 0.61 & $-0.001 \mathrm{~kg} \mathrm{~L}^{-1}$ & $0.30(0.38)^{*}$ & $0.30(0.37)^{*}$ \\
\hline
\end{tabular}

*Values in parentheses apply for $\rho$ when SWE $>100 \mathrm{~mm}$.
TCD

8, 1973-2003, 2014

Simulating more accurate snow maps for Norway

T. M. Saloranta

Title Page

Abstract

Introduction

Conclusions

References

Tables

Figures

14

$>1$

4

Back

Close

Full Screen / Esc

Printer-friendly Version

Interactive Discussion 


\section{sN senorge.no weather water [5now climate}

\begin{tabular}{|l|l|l|l|l|l|l|}
\hline-1 year & -1 week & -1 day & Today & +1 day & +1 week & +1 year \\
\hline
\end{tabular}
\begin{tabular}{|l|l|l|}
\hline Grid data & P Point/line data & Pvent data \\
\hline
\end{tabular}

Fig. 1. Example of a snow map for Norway (www.senorge.no) showing snow depth in 18 December 2013.

\section{TCD}

8, 1973-2003, 2014

Simulating more accurate snow maps for Norway

T. M. Saloranta

Title Page

\section{Abstract}

Introduction

Conclusions

References

Tables

Figures

14

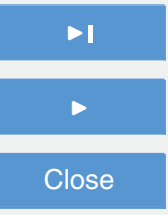

Back

Close

Full Screen / Esc

Printer-friendly Version

Interactive Discussion

(c) (1) 


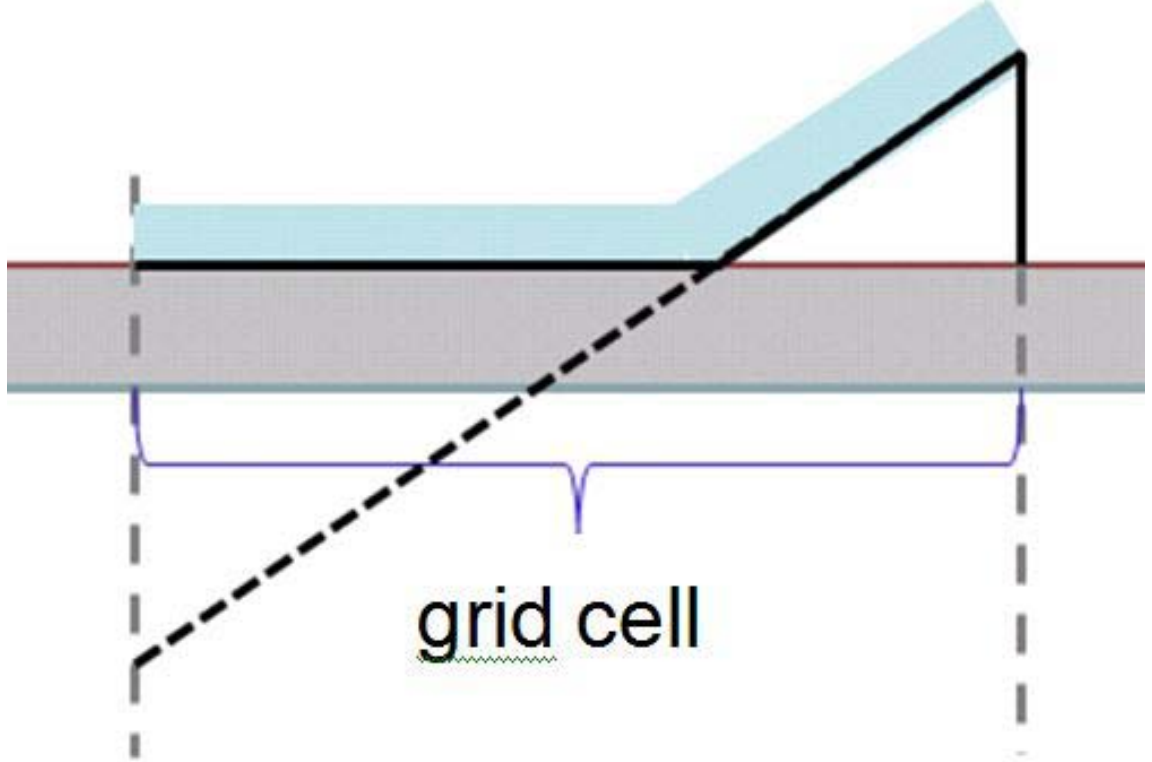

Fig. 2. Schematic illustration of the snow distribution and fraction of snow-covered area (SCA) model. The solid black line denotes the remaining uniformly distributed "old" snow pack (with $\mathrm{SCA}=0.35$ ) having a layer of new snow on top (light blue). Due to the new snow layer SCA $=1$ for the grid cell. The black dashed line below the ground denotes the completely melted part of the original uniform snow distribution (i.e. since the start of the main snow melt season).

\section{TCD}

8, 1973-2003, 2014

\section{Simulating more} accurate snow maps for Norway

T. M. Saloranta

\section{Title Page}

Abstract

\section{Introduction}

Conclusions

References

Tables

Figures

14

$\rightarrow 1$

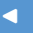

Back

Close

\section{Full Screen / Esc}

Printer-friendly Version

Interactive Discussion 


\section{$\log 10(S W E)$}

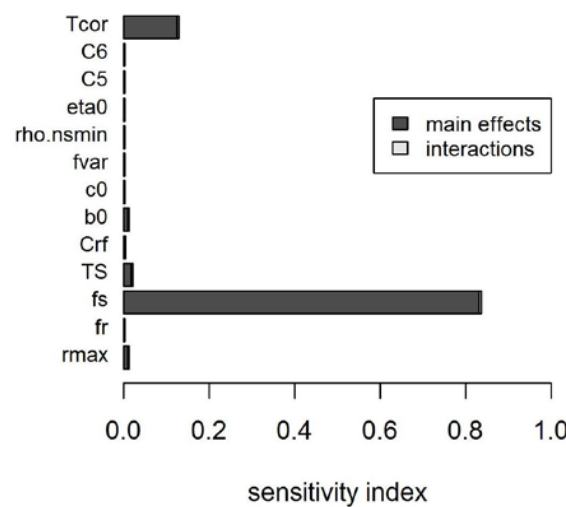

rho

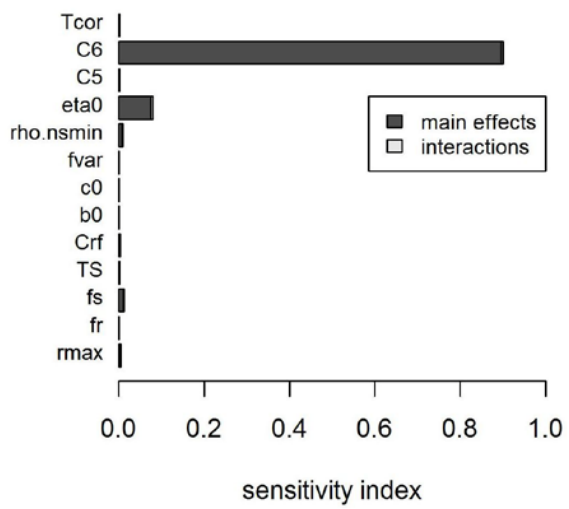

8, 1973-2003, 2014

Simulating more accurate snow maps for Norway

T. M. Saloranta

Title Page

Abstract

Introduction

Conclusions

References

Tables

Figures

14

D

4

Back

Close

Full Screen / Esc

Printer-friendly Version

Interactive Discussion 
(a)

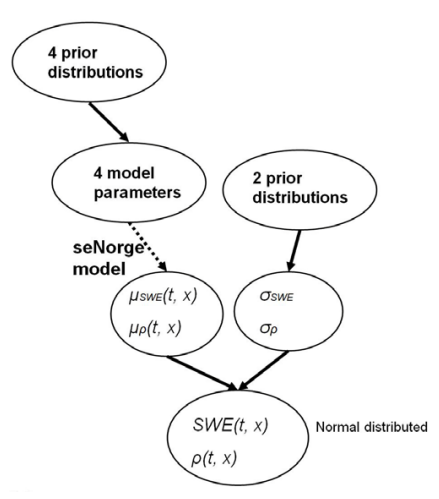

TCD

8, 1973-2003, 2014

Simulating more

accurate snow maps

for Norway

T. M. Saloranta

(b)

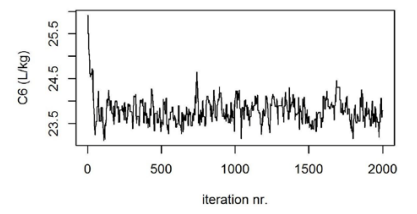

(c)

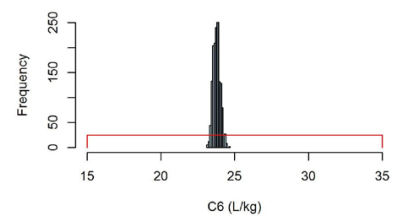

Fig. 4. (a) Graphical illustration of the Bayesian model assumed in the MCMC simulation, where the solid and dashed arrows denote stochastic and deterministic relationships, respectively. The observations of SWE and $\rho$ at a particular date and location $(t, x)$ are assumed to be normal distributed with means $\mu$ (separate $\mu$ for each date and location) and standard deviations $\sigma$ (assumed constant in time and space). The distributions of $\mu$ 's and $\sigma$ 's are estimated in the MCMC simulation. The means of SWE and $\rho$ (i.e. the $\mu$ 's) over a $1 \mathrm{~km} \times 1 \mathrm{~km}$ grid cell at a given date can be simulated by the seNorge snow model, and thus there is a deterministic link between the 4 model parameters and the $\mu$ 's. Consequently, instead of estimating the distributions of $\mu$ 's directly we estimate the distributions of the model parameters. Finally, our prior knowledge on the distributions of the model parameters and $\sigma$ 's are expressed in the prior distributions. (b) Simulated parameter chain of one of the four estimated parameters $C_{6}$ in the MCMC-simulation, and (c) its prior (solid line) and posterior (histogram) distributions. The histogram is based on the chain values in (b) after the burn-in period of 500 iterations.

Title Page

Abstract

Introduction

Conclusions

References

Tables

Figures

14

DI

4

Back

Close

Full Screen / Esc

Printer-friendly Version

Interactive Discussion 
SWE

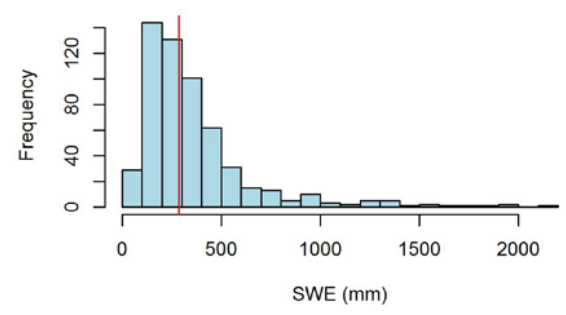

year

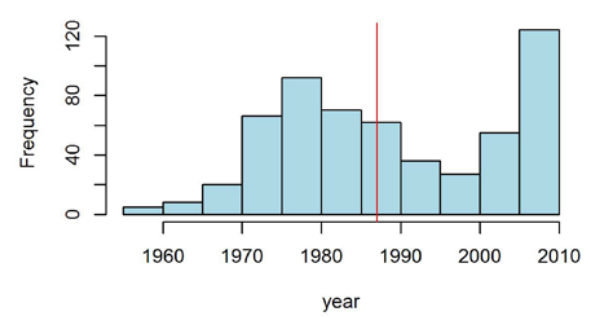

elevation

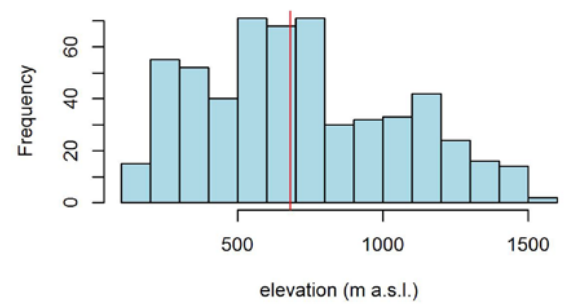

rho

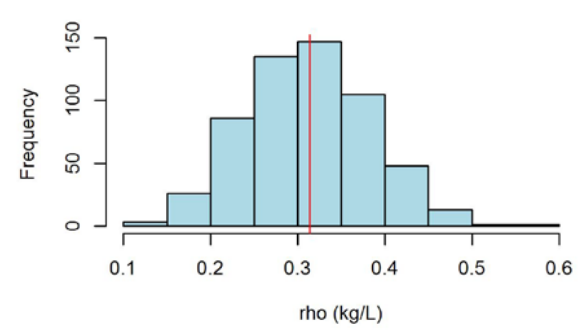

day $\mathrm{nr}$.

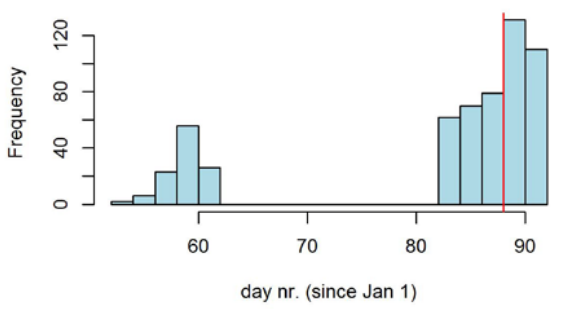

latitude

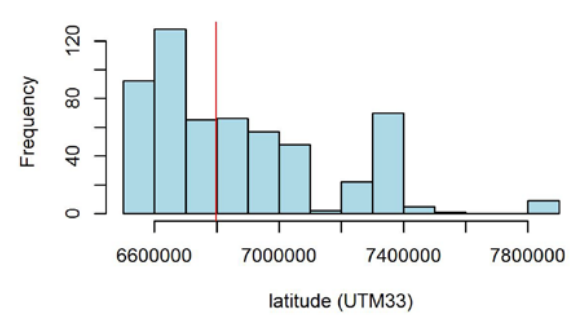

TCD

8, 1973-2003, 2014

\section{Simulating more} accurate snow maps for Norway

T. M. Saloranta

\section{Title Page}

4

Back

\section{Full Screen / Esc}

Printer-friendly Version tiotemporal characteristics of the 565 snow observations used in model parameter estimation (MCMC simulation). The red lines denote the median values. 
(a)

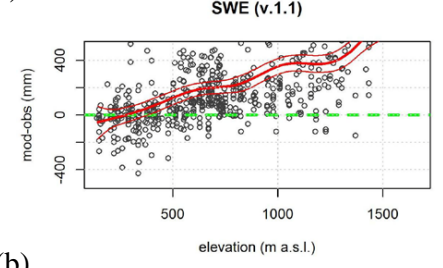

(b)

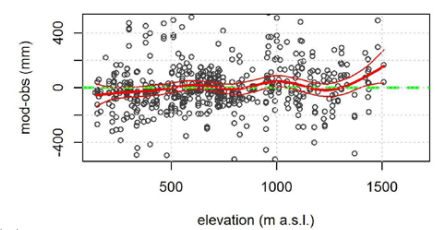

(c)

SWE (v.1.1.1)

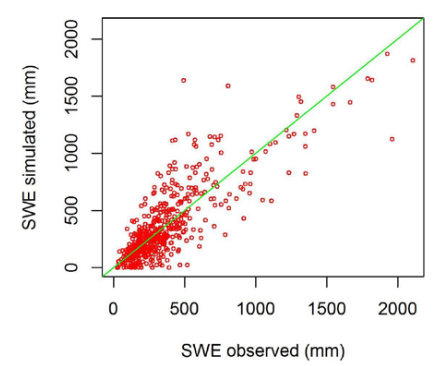

rho (v.1.1)

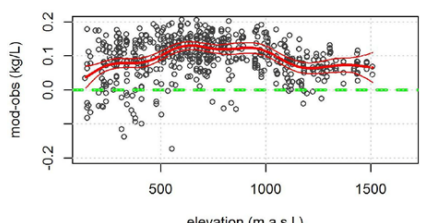

rho (v.1.1.1)

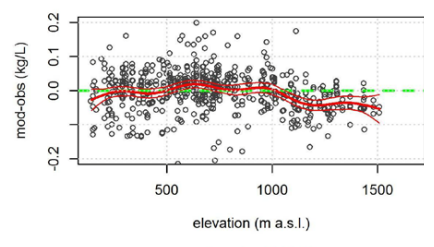

rho (v.1.1.1)

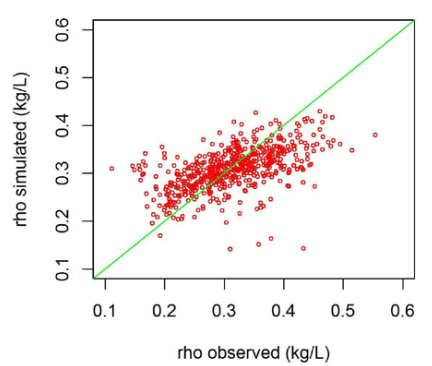

TCD

8, 1973-2003, 2014

\section{Simulating more}

accurate snow maps

for Norway

T. M. Saloranta

Title Page

Abstract

Introduction

Conclusions

References

Tables

Figures

14

$\rightarrow 1$

4

Back

Close

Full Screen / Esc

Printer-friendly Version

Interactive Discussion 